\title{
Ethnicity, sleep, mood, and illumination in postmenopausal women
} Daniel F Kripke*1, Girardin Jean-Louis ${ }^{3}$, Jeffrey A Elliott ${ }^{1}$, Melville R Klauber ${ }^{2}$, Katharine $\mathrm{M} \mathrm{Rex}^{1}$, Arja Tuunainen ${ }^{4}$ and Robert D Langer ${ }^{2}$

\author{
Address: ${ }^{1}$ Departments of Psychiatry, University of California, San Diego, CA, USA, ${ }^{2}$ Family and Preventive Medicine and The Sam and Rose Stein \\ Institute for Research on Aging, University of California, San Diego, CA, USA, ${ }^{3}$ Department of Psychiatry, SUNY Downstate Medical Center, \\ Brooklyn, NY, USA and ${ }^{4}$ Department of Psychiatry, University of Helsinki, Helsinki, Finland \\ Email: Daniel F Kripke* - dkripke@ucsd.edu; Girardin Jean-Louis - jeanlouisg@yahoo.com; Jeffrey A Elliott - jelliott@ucsd.edu; \\ Melville R Klauber - sklau77557@aol.com; Katharine M Rex - krex@ucsd.edu; Arja Tuunainen - atuunain@mappi.helsinki.fi; \\ Robert D Langer - rdlanger@ucsd.edu \\ * Corresponding author
}

Published: 07 April 2004

BMC Psychiatry 2004, 4:8
Received: 01 October 2003

Accepted: 07 April 2004

This article is available from: http://www.biomedcentral.com/I47I-244X/4/8

(c) 2004 Kripke et al; licensee BioMed Central Ltd. This is an Open Access article: verbatim copying and redistribution of this article are permitted in all media for any purpose, provided this notice is preserved along with the article's original URL.

\begin{abstract}
Background: This study examined how ethnic differences in sleep and depression were related to environmental illumination and circadian rhythms.

Methods: In an ancillary study to the Women's Health Initiative, 459 postmenopausal women were recorded for one week in their homes, using wrist monitors. Sleep and illumination experience were estimated. Depression was self-rated with a brief adjective check list. Affective diagnoses were made using the SCID interview. Sleep disordered breathing was monitored with home pulse oximetry.

Results: Hispanic and African-American women slept less than European-American women, according to both objective recordings and their own sleep logs. Non-European-American women had more blood oxygen desaturations during sleep, which accounted for $26 \%$ of sleep duration variance associated with ethnicity. Hispanic women were much more depressed. Hispanic, AfricanAmerican and Native-American women experienced less daily illumination. Less daily illumination experience was associated with poorer global functioning, longer but more disturbed sleep, and more depression.

Conclusions: Curtailed sleep and poor mood were related to ethnicity. Sleep disordered breathing was a factor in the curtailed sleep of minority women. Less illumination was experienced by non-European-American women, but illumination accounted for little of the contrasts between ethnic groups in sleep and mood. Social factors may be involved.
\end{abstract}

\section{Background}

Sleep disturbances and depression seem particularly prominent among postmenopausal women. There has been little explanation of the apparently-more-severe sleep disturbances among minorities, though one factor appears to be obesity influencing sleep disordered breathing [1-5]. Data on ethnic differences in depression have been mixed. The National Comorbidity Survey Replication found the 12-month odds ratio for major depressive disorder as $1.3(0.8-2.295 \%$ C.I.) for non-Hispanic 
Blacks and 1.6 (1.0-2.6 95\% C.I.) for Hispanics as compared to non-Hispanic Whites; however, the lifetime prevalences for the minorities were not elevated [6]. NHanes III found more major depression among Whites than among Blacks and Mexican Americans ages 17-39 years, but dysthymia was greater among Blacks and Mexican Americans [7]. For ages 54-65, the Health and Retirement Survey found more major depression among African Americans $(\mathrm{OR}=1.44,95 \%$ C.I. $=1.02-2.04)$ and Hispanics (OR-1.16, 95\% C.I. $=0.93-1.44)$ than among Whites, but these odds ratios dropped below 1.0 when adjusted for sociodemographic, health, and economic covariates [8]. Thus, age, social factors, and diagnostic perspectives seem to complicate ethnic contrasts in depression.

The complex causal inter-relationships of illumination, sleep disturbances, depression, circadian rhythms, and general health have been difficult to resolve. Each of these factors might be influenced by aging, by ethnic factors, and by social factors related to ethnicity. Previously, our group found that low daily illumination was associated with both greater depressive symptoms and greater sleep complaints in the population as a whole $[9,10]$. Bright light treatment has been an effective treatment of depression in short-term studies of both nonseasonal and seasonal depression $[11,12]$, but long-term studies are lacking. None of the controlled light treatment trials for nonseasonal depression have included sleep recording. Bright light has been recommended for treatment of various sleep disorders [13], but very few experimental trials have been reported. It is known that illumination may influence circadian adjustment, and conversely, circadian adjustment (especially the time of arising) may influence a person's exposure to daylight. Without artificial bright light treatment, wellness and energy influencing time outdoors in daylight may be major factors influencing daily light exposure. Light may have a causal role in depression, but depression could also influence how much people expose themselves to bright daylight. Sleep disturbances and circadian adjustment may influence either depression or general wellness and vice versa.

This study examined ethnic differences in sleep and depression to explore how environmental illumination and circadian rhythms might interact with sleep, depression, and ethnicity. Extensive home recordings for this study were analyzed here to see how ethnicity, illumination, sleep, and mood each was associated with the other factors with which they might causally interact. The contribution of sleep disordered breathing was also considered. The cross-sectional methodology was capable of exploring the strength of associations but was not capable of distinguishing causal pathways.

\section{Methods}

The current study analyzed the baseline data of a prospective study organized to explore whether objectively-measured sleep durations predict mortality. From among volunteers in the Observational Study enrolled at the San Diego Vanguard Clinical Center for the Women's Health Initiative [14], 459 postmenopausal women were recruited to participate in this ancillary study. This was not a representative population sample. Recruitment focused on subjects with particularly short or long reported sleep, older age, and minority ethnicity from within the larger group of volunteers for the Women's Health Initiative. Each subject signed written informed consent under supervision of UCSD's Institutional Review Board, consistent with the World Medical Association Declaration of Helsinki. Results from melatonin measurements and SCID psychiatric interviews of these women and some aspects of their sleep data have been described elsewhere [15-20].

Each woman wore an Actillume I wrist monitor (Ambulatory Monitoring, Ardsley, New York) for up to one week. The Actillume included a linear accelerometer and a photometric transducer used to continuously measure the illumination experienced in lux. From accelerometer indications of wrist activity, in-bed sleep-wake state was estimated for one-minute epochs, using a validated computer algorithm, supplemented by "Webster's rules" [21] and hand-editing, e.g., to delete epochs when the device was removed for bathing. "Webster's rules" improve the specificity of scoring of out-of-bed sleep and the accuracy of 24-hour sleep scoring at the expense of over-estimating the amount of wake within sleep. In post-menopausal women, with this scoring method, actigraphic total sleep time correlated $r=0.97$ with polysomnographic scoring, but there was a mean underestimation of EEG sleep time of about 30 minutes [21]. The objective in-bed nocturnal sleep durations were averaged for a mean of 6.8 nights (SD 0.6) per subject. The log [base 10] of Actillume lux measurements was used as the measure of experienced illumination, since biological effects of illumination (in shifting circadian phase or suppressing melatonin, for example) may be roughly linear to the log of illumination along the central portion of a sigmoid dose-response curve $[22,23]$. Values of less than 1 lux were set to $\log _{10}[\operatorname{lux}]=0$, to avoid giving weight to very small variations in illumination which may lack physiologic effect. A 24-hour cosine was fit to the week's measurements, to correct for time-of-day biases in missing data, and the mesor (fitted cosine's mean) was employed as the best estimate of daily illumination.

For several nights during the study, the women wore a VX4 finger pulse oximeter, but many recordings were lost due to technical problems, especially intermittent failures 
of VX4 instruments. Valid data were available for at least one night for 358 women. Of these, there were data for 2 nights for $80 \%$, for 3 nights for $44 \%$, and for 4 nights for $3 \%$. The oxygen desaturation index $4 \%$ or ODI 4 was computed as the number of oxygen desaturations of $\geq 4 \%$ per hour of sleep, averaged over the available nights. The ODI4 is very highly correlated with the respiratory disturbance index, the most validated indicator of sleep disordered breathing [24]. The oximetry methodology had the advantage of facilitating multi-night assessment of sleep disordered breathing in the home setting.

Daily sleep-log reports of subjective sleep duration were averaged for the recording week. At the end of the week, the 10-item sleep questionnaire used at Women's Health Initiative intake [3] was readministered to measure subjective sleep quality, trouble falling asleep, waking up several times a night, waking up earlier than planned, and trouble getting back to sleep. At the end of the recording week, subjects also completed a brief mood scale which included 6 items from the CES-D [25]. To avoid confounding sleep complaints with depression, the item about restless sleep was removed, leaving 5 items. Although this scale has only modest validity [19], it served as a general indicator of the degree to which the subjects were depressed at the moment. Affective diagnoses and ratings of Global Assessment of Functioning were obtained from SCID interviews [26] conducted by DFK, usually within 2 weeks of the recordings.

Subjects provided around-the-clock fractional urine specimens for analysis of 6-sulfatoxymelatonin (aMT6s), the major urinary metabolite of melatonin, as described previously [27]. Most subjects provided urine specimens for two 24-hour intervals during the week of actigraphic recording. From these assays, timing and volume data, it was possible to estimate total daily melatonin production and the parameters of the circadian rhythm of melatonin excretion.

Participants self-identified their ethnicity as EuropeanAmerican (White), Hispanic (or Latino) regardless of race,
African-American (Black), Asian (or Pacific Islander), and Native-American (or Aleut). Analyses of covariance (ANCOVA) were used to determine the influence of ethnicity ( 5 levels) as a fixed factor, as well as various covariates, especially age, education, and illumination. Also, in order to assess the strength of associations, partial correlations were calculated, using presence or absence of each ethnic group as a pseudo-variable for control. Supplementary rank-order correlations were used for skewed data.

\section{Results}

Of 459 women who participated in the study, because of missing data items, only 416-450 could be included in most analyses (300-350 for ODI4 analyses). Their ages averaged mean (SD) 67.7 (7.9) years overall, but the European-Americans averaged 70 years of age, whereas each of the four non-European groups averaged 62 years of age $(\mathrm{p}$ $<0.001$ ), as shown in Table 1 . Their mesor of $\log _{10}$ [lux] illumination had a mean (SD) of $1.10(0.27)$ with a range from 0.11 to 2.12 . This corresponds to over a hundredfold range of daily illumination experienced. Objective inbed sleep averaged (SD) $360 \mathrm{~min}$. (55), without correcting for the likely $30 \mathrm{~min}$. underestimation due to actigraphic scoring. Sleep log reported sleep times averaged $412 \mathrm{~min}$. (60), and their sleep had averaged $408 \mathrm{~min}$. (69) in estimates of typical sleep for the past 4 weeks recorded at intake to the WHI program. The correlation of objective and sleep log sleep times was $r=0.51(p<0.001)$. Thirty of the women were diagnosed as having a major or minor depressive disorder at the time of the study by SCID interviews. On the 5 CES-D items, the mean (SD) score was 1.0 (1.9), indicating a highly skewed distribution, with over half the women reporting no mood symptoms.

To examine factors related to depression, ethnicities were contrasted. The depression scores adjusted for education and mesor $\log _{10}$ [lux] were more than twice as high among Hispanics as among European-American women, as shown in Table $2(\mathrm{p}<0.001)$. Age was not related to mood in this analysis. Similarly, $13 \%$ of Hispanic women received a SCID diagnosis of a current mood disorder as compared to $6 \%$ of European-Americans ( $\mathrm{p}<0.05)$. Illu-

Table I: Demographics of 5 ethnic groups: means ( $95 \%$ confidence intervals)

\begin{tabular}{llllll}
\hline & European American & Hispanic American & African American & $\begin{array}{l}\text { Asian-Pacific } \\
\text { American }\end{array}$ & $\begin{array}{l}\text { Native-Aleut } \\
\text { American }\end{array}$ \\
\hline Percentage of Sample & $72.2 \%$ & $13.7 \%$ & $9.4 \%$ & $4.0 \%$ & $0.7 \%$ \\
Age & $69.8(69.1-70.6)$ & $62.4(60.6-64.2)$ & $61.7(59.4-64.0)$ & $61.7(58.0-65.5)$ & $62.3(48.8-75.8)$ \\
Education ( years) & $14.6(14.4-15.0)$ & $13.0(12.0-14.0)$ & $14.4(13.4-15.4)$ & $15(13.6-16.4)$ & $13.4(9.8-16.8)$ \\
Body Mass Index & $26.5(25.7-27.2)$ & $28.0(26.5-29.6)$ & $30.3(28.3-32.4)$ & $23.3(21.6-25.0)$ & 29.8 \\
Employed & $16 \%(12 \%-21 \%)$ & $43 \%(30 \%-56 \%)$ & $46 \%(31 \%-62 \%)$ & $50 \%(25 \%-75 \%)$ & $100 \%$ \\
Currently Married & $60 \%(55 \%-65 \%)$ & $62 \%(50 \%-75 \%)$ & $57 \%(42 \%-72 \%)$ & $78 \%(58 \%-98 \%)$ & $67 \%(1-100 \%)$ \\
Current smoking & $7 \%(3 \%-11 \%)$ & $19 \%(5 \%-33 \%)$ & $29 \%(11 \%-48 \%)$ & $0 \%$ & $0 \%$ \\
\hline
\end{tabular}


Table 2: Covariate-adjusted mean measures for ethnic groups ( $95 \%$ confidence intervals)

\begin{tabular}{|c|c|c|c|c|c|}
\hline & European American & Hispanic American & African American & $\begin{array}{l}\text { Asian-Pacific } \\
\text { American }\end{array}$ & $\begin{array}{l}\text { Native-Aleut } \\
\text { American }\end{array}$ \\
\hline Depression score & $0.91(0.69-1.12)$ & $2.14(1.64-2.7 I)$ & $0.56(0-1.19)$ & $1.01(0.14-1.88)$ & $0(0-1.75)$ \\
\hline mesor $\log _{10}[\operatorname{lux}]$ & $1.14(1.11-1.17)$ & $0.98(0.92-1.05)$ & $0.94(0.86-1.03)$ & I.II (0.98-I.23) & $0.83(0.54-1.12)$ \\
\hline objective sleep (min.) & $369(362-375)$ & $350(334-365)$ & $315(297-333)$ & $341(316-365)$ & $357(303-423)$ \\
\hline subjective sleep (min.) & $418(4 \mid I-425)$ & $395(379-4 I I)$ & $378(360-397)$ & $421(395-448)$ & $388(324-453)$ \\
\hline acrophase of sleep & $2: 59(2: 52-3: 06)$ & $2: 43(2: 26-3: 00)$ & $2: 57(2: 37-3: 18)$ & $3: 48(3: 19-4: 17)$ & $2: 38(1: 28-3: 53)$ \\
\hline ODI4 & $8.8(7.6-10.0)$ & I I.4 (8.4-14.3) & $12.4(9.1-15.8)$ & $13.7(8.2-19.2)$ & $31.1(12.6-49.6)$ \\
\hline
\end{tabular}

mination was a significant covariate $(\mathrm{p}<0.025)$ of mood scores. The simple Spearman correlation of illumination and depression symptoms was $\mathrm{r}_{\mathrm{S}}=-0.14(\mathrm{p}<0.005)$. The partial correlation of depression symptoms with illumination was $r_{p}=-0.11(p=<0.025)$, controlling for age, education, and ethnicity. However, controlling also for income reduced $r_{p}$ to -0.08 (NS). The partial correlation of illumination with the presence of any SCID mood disorder was low: $r_{p}=-0.08(N S)$.

The SCID global assessment of functioning scale was not significantly impacted by ethnicity, with covariates of age, education, and illumination exposure in the model. However, the covariates were all highly significant $(\mathrm{p}<0.001)$. Adding income as a covariate for global assessment of functioning did not substantially change these results. The partial correlation of illumination with the SCID global assessment of functioning, controlling for age, education, and ethnicity, was $r_{p}=0.22(p<0.001)$, but adding control for income reduced the partial correlation to $r_{p}=0.16$ $(\mathrm{p}<0.001)$.

Neither the mood scale nor SCID diagnoses of depression were significantly correlated with objective sleep duration. There was a trend for more depressed mood to be associated with both the shortest and longest sleep durations, but this was not significant.

Controlling for age and education in ANCOVA, ethnicity was significantly related to mesor $\log _{10}[$ lux] illumination exposure $(p<0.001)$ as shown in Table 2. These $\log _{10}[$ lux] values indicated that European Americans received twice the daily illumination as Native Americans on a linear scale.

As detailed in Table 2, objective sleep time was significantly related to ethnicity $(\mathrm{p}<0.001)$ in ANCOVA controlled for covariates of illumination ( $\mathrm{p}<0.001)$, age (NS), education (NS), and depression score (NS). From another viewpoint, the partial correlation of objective sleep duration with mesor $\log _{10}[\operatorname{lux}]$ was $r_{p}=-0.20$ (p < $0.001)$, controlling for age and controlling for ethnicity coded as pseudovariables. That is, those experiencing more illumination slept less. Further adjustment for mood scores or presence of SCID depression did not substantially alter this partial correlation. Melatonin excretion (aMT6s $\log _{10}$ [mesor]), estimated nightly duration of excretion, offset timing, and acrophase deviation were not significant covariates of objective sleep duration when included in the ANCOVA model. Although ethnicity was likewise related to sleep-log-reported sleep durations $(\mathrm{p}<$ 0.001 ), illumination, education, and age were not significant covariates. The timing (acrophase) of sleep was influenced by ethnicity ( $p<0.01)$, mesor $\log _{10}[$ lux $]$ ( $p<$ $0.005)$, and the timing (acrophase) of light ( $\mathrm{p}<0.05)$, but education and age were not significant covariates. The partial correlation of mesor $\log _{10}$ [lux] with the acrophase of sleep was $r_{p}=-0.14(p<0.005)$, controlling for age and ethnicity, indicating that those who received more daily illumination went to bed and awakened earlier. Out-ofbed (daytime) sleep was not significantly related to ethnicity or illumination.

In partial correlations controlling for age and ethnicity, sleep-log-reported sleep durations were positively correlated with subjective sleep quality $\left(r_{p}=0.27, p<0.001\right)$, and negatively correlated with reported trouble falling asleep $\left(r_{p}=-0.28, p<0.001\right)$, waking up several times a night $\left(\mathrm{r}_{\mathrm{p}}=-0.11, \mathrm{p}<0.025\right)$, waking up earlier than planned $\left(r_{p}=-0.30, p<0.001\right)$, and trouble getting back to sleep $\left(r_{p}=-0.36, p<0.001\right)$. Although mesor $\log _{10}[$ lux] was not significantly correlated with sleep-log sleep durations, it was similarly positively correlated with sleep quality $\left(r_{p}=0.17, p<0.005\right)$, and negatively correlated with reported trouble falling asleep $\left(r_{p}=-0.17, p<0.005\right)$, waking up several times a night $\left(r_{p}=-0.18, p<0.001\right)$, waking up earlier than planned $\left(r_{p}=-0.09, p<0.10\right)$, and trouble getting back to sleep $\left(r_{p}=-0.11, p<0.025\right)$. As would be expected, depression symptoms and the presence of a SCID mood disorder had significant inverse relationships to subjective sleep quality and positive associations with subjective sleep complaints (details not presented.) Melatonin excretion (aMT6s $\log _{10}[$ mesor]) was 
not significantly related to sleep symptoms or quality, with control for age and ethnicity.

The ODI4 range in these women was 0 to 57 desaturations per hour: the 75th percentile was 12 , and the 90th percentile was 21 . Oxygen desaturations were substantially related to ethnicity, in ANCOVA controlled for age and education $(\mathrm{p}<0.025)$. Table 2 gives the adjusted ODI4 means by ethnicity. Although body mass index correlated substantially with ODI4 (Spearman $\mathrm{r}_{\mathrm{s}}=0.28$, $\mathrm{p}<0.001$ ), adjustment for body mass index had little effect on ethnic differences. ODI4 was negatively correlated with actigraphic sleep duration $\left(r_{p}=-0.28, p<0.001\right)$. Testing the ethnicity effect on sleep duration in ANCOVA controlled for age, education, and illumination, adjusting for ODI4 reduced by $26 \%$ the sum of squares explained by ethnicity ( $\mathrm{p}<0.001$ ). ODI4 was weakly positively correlated with subjective wake after sleep onset $\left(r_{p}=0.11, p<0.05\right)$. ODI4 was not significantly correlated with subjective sleep duration, sleep quality, trouble falling asleep, waking early, or trouble getting back to sleep, nor with depression, Global Assessment of Functioning, or illumination.

In ANCOVA, aMT6s $\log _{10}$ [mesor] was not related to ethnicity or illumination but decreased significantly with age $(p<0.001)$. The timing of the melatonin excretion acrophase and offset were both related to $\log _{10}[$ lux] in partial correlations controlled for age and ethnicity with $r_{p}=-0.14$ ( $p<0.025)$, i.e., the brighter the illumination, the earlier the aMT6s acrophase and offset. Melatonin onset time was not significantly related.

\section{Discussion}

In this sample, Hispanic and African-American women reported that they slept less than European-American women, reporting subjective sleep durations quite similar to that of the larger national WHI sample [3]. This contrast was confirmed by the objective recordings. A limitation of the results is that recruiting for women with particularly short or long sleep could have biased the means for ethnic groups. Although the actigraphic scoring algorithm may underestimate nocturnal EEG sleep by an average of $30 \mathrm{~min}$. [21], these data still confirm other studies showing that objective sleep duration is often less than the sleep duration that people report. This is probably because people do not subtract from their reported sleep durations all of their wake after sleep onset.

Sleep apnea was one of the sources of reduced sleep in non-European women. As has been previously described [28], sleep apnea is pervasive in this age group. ODI4 values were substantially higher in non-European women. Since sleep apnea is often thought to be associated with excessive sleep, it was surprising that ODI4 was associated with shorter sleep but not otherwise much related to sleep symptomatology, depression, or disability. It has been repeatedly shown that the ODI4 is a very reliable correlate of respiratory disturbance indexes derived from full polysomnography [24]. Additional reliability in these recording results from the multiple ODI4 recording nights for most women included in the ODI4 analyses. Community samples with both actigraphic and polysomnographic technologies have found more modest associations of symptomatology with sleep disordered breathing than have samples derived from sleep clinics $[24,29,30]$.

As has been previously noted in larger portions of the WHI sample [14], Hispanic postmenopausal women reported markedly more depression. This was confirmed by the SCID interviews [27]. The reasons for poor sleep and poor mood among non-European women have not been immediately apparent. Social and cultural influences could be factors, both in the development of depression and in expressiveness of symptoms. A higher risk ratio for 12-month depression was found among Hispanics in the National Comorbidity Study replication $(1.6,95 \%$ CI 1.0-2.6), but was not separated by gender [31]. No linear correlations were noted between sleep duration and the indices of depression. A U-shaped relationship of depression to both long and short self-reported sleep was evident in the national Women's Health Initiative sample [3]; there was a similar trend in these data but no significant relationship.

Low daily illumination was weakly associated with depressed mood. Hispanic women experienced lower illumination, but in ANCOVA models, controlling for illumination eliminated only $12 \%$ of the variance in depression attributable to ethnicity. It is plausible that low illumination was a source of depressed mood, but the converse would also be plausible. That is, depression might influence women to spend less time outdoors in daylight. The more substantial correlation of illumination with the global assessment of functioning may be consistent with the hypothesis that poor functioning causes poor illumination experience which then may contribute to depression, perhaps engendering a circular process. Low illumination experience might also be a contributing cause to the poor global function with which it was associated. It is plausible that income directly affects global function, as functional ability no doubt affects income, but income may also influence global functioning indirectly through illumination experience, e.g., a wealthy woman with a home garden and a golf club membership might experience more daylight than a woman of modest means living in an apartment.

Since illumination was negatively correlated with objective sleep duration (those experiencing less illumination slept slightly longer), low illumination provided no expla- 
nation for the abbreviated sleep of non-European women. Nevertheless, those experiencing lower illumination reported more complaints about sleep such as poor sleep quality, trouble falling asleep, waking up several times a night, waking up earlier than planned, etc. These complaints may result from low mood, with which they were associated, or even from spending too long a time in bed. Low illumination may well contribute to the distress engendering sleep complaints.

It appears that women who experienced more illumination arose somewhat earlier. Increased illumination may tend to advance the circadian system, but the converse that those who arise early may receive more outdoor illumination is also plausible. Similarly, those experiencing more illumination had a somewhat more advanced melatonin rhythm, possibly in part due to suppression of melatonin by morning light and in part due to a phase advance of the circadian clock. Nevertheless, as reported elsewhere, the amount of melatonin excreted was not related to sleep symptoms, duration, or quality, nor could melatonin account for ethnic differences in sleep.

In conclusion, low-illumination has a small relationship to depression and sleep disturbances, but it accounted for little of the poor sleep and low mood of non-European postmenopausal women. Sleep disordered breathing appears to abbreviate sleep in non-European women, but it produces little subjective distress.

\section{Competing interests}

None declared.

\section{Authors' contributions}

DFK was the PI of the study, oversaw all aspects of data collection, conducted all SCID interviews, and drafted the manuscript. GJ-L carried out data collection, organization and analyses. MRK participated in the design of the study and performed statistical analyses. KMR participated in the design and coordination of the study. AT performed data extraction and analyses. RDL is the PI of the WHI Study in San Diego and participated in the design and coordination of the study.

All authors read and approved the final manuscript.

\section{Acknowledgments}

Supported by the National Institutes of Health HL55983, AG I5763, AGI 2364, and HL6I280. Joseph D. Assmus, Mary Anne Mowen, Stephanie Oprendek, and Geraldine Wallace-Guy assisted this study.

\section{References}

I. Ancoli-Israel S, Klauber MR, Stepnowsky C, Estline E, Chinn A, Fell R: Sleep disordered breathing in African-American elderly. $\mathrm{Am}$ J Resp Crit Care Med 1995, 152:1946-1949.
2. Foley DJ, Monjan AA, Izmirlian G, Hays JC, Blazer DG: Incidence and remission of insomnia among elderly adults in a biracial cohort. Sleep 1999, 22:S373-S378.

3. Kripke DF, Brunner R, Freeman R, Hendrix S, Jackson RD, Masaki K et al.: Sleep complaints of postmenopausal women. Clinical Journal of Women's Health 200I, I:244-252.

4. Hollander LE, Freeman EW, Sammel MD, Berlin JA, Grisso JA, Battistini M: Sleep quality, estradiol levels, and behavioral factors in late reproductive age women. Obstet Gynecol 200I, 98:39I-397.

5. O'Connor GT, Lind BK, Lee ET, Nieto J, Redline S, Samet JM, Boland $\mathrm{LL}$, Walsleben JA, Foster GL: Variation in symptoms of sleep-disordered breathing with race and ethnicity: The Sleep Heart Health Study. Sleep 2003, 26:74-79.

6. Kessler RC, Berglund P, Demler O, Jin R, Koretz D, Merikangas KR, Rush AJ, Walters EE, Wang PS: The epidemiology of major depressive disorder. JAMA 2003, 289:3095-3105.

7. Jonas BS, Brody D, Roper M, Narrow WE: Prevalence of mood disorders in a national sample of young American adults. Soc Psychiatry Psychiatr Epidemiol 2003, 38:618-624.

8. Dunlop DD, Song J, Lyons JS, Manheim LM, Chang RW: Racial/ethnic differences in rates of depression among preretirement adults. Am J Public Health 2003, 93: $1945-1952$.

9. Espiritu RC, Kripke DF, Ancoli-Israel S, Mowen MA, Mason WJ, Fell $\mathrm{RL}$ et al:: Low illumination by San Diego adults: association withatypical depressive symptoms. Biol Psychiatry 1994, 35:403-407.

10. Kripke DF, Juarez S, Cole RJ, Ancoli-Israel S, Hauri PJ, Wisbey JA et al: Adult illumination exposures and some correlations with symptoms. In Evolution of Circadian Clock Edited by: Hiroshige T, Honma K. Sapporo: Hokkaido University Press; 1994:349-360.

II. Kripke DF: Light treatment for nonseasonal depression: speed, efficacy, and combined treatment. J Affect Dis 1998, 49:109-117.

12. Terman M, Terman JS, Ross DC: A controlled trial of timed bright light and negative air ionization for treatment of winter depression. Arch Gen Psychiatry 1998, 55:875-882.

13. Dijk D-J, Boulos Z, Eastman Cl, Lewy AJ, Campbell SS, Terman M: Light treatment for sleep disorders: Consensus report. II. Basic properties of circadian physiology and sleep regulation. J Biol Rhythms 1995, I 0: I 13-125.

14. Langer RD, White E, Lewis CE, Kotchen JM, Hendrix SL, Trevisan M: The Women's Health Initiative Observational Study: Baseline characteristics of participants and reliability of baseline measures. Ann Epidemiol 2003, 13:SI07-SI 21

15. Kripke DF, Elliott JA, Youngstedt SD, Smith IS: Melatonin: Marvel or marker? Annals of Medicine 1998, 30:8I-87.

16. Jean-Louis G, Kripke DF, Ancoli-Israel S, Klauber MR, Sepulveda RS, Mowen M-A et al:: Circadian sleep, illumination, and activity patterns in women: influences of aging and time reference. Physiology \& Behavior 2000, 68:347-352.

17. Tuunainen A, Kripke DF, Elliott JA, Assmus JD, Rex KM, Klauber MR et al.: Depression and endogenous melatonin in postmenopausal women. J Affect Dis 2002, 69:149-158.

18. Wallace-Guy GM, Kripke DF, Jean-Louis G, Langer RD, Elliott JA, Tuunainen $A$ : Evening light exposure: Implications for sleep and depression. I Am Geriatr Soc 2002, 50:738-739.

19. Tuunainen A, Langer RD, Klauber MR, Kripke DF: Short version of theCES-D (Burnam screen) for depression in reference to the structured psychiatric interview. Psychiat Res 200I, 103:26I-270

20. Yoon I-Y, Kripke DF, Elliott JA, Langer RD: Naps and Circadian Rhythmsin Postmenopausal Women. Journal of Gerontology 2004 in press.

2I. Jean-Louis G, Kripke DF, Cole RJ, Assmus JD, Langer RD: Sleep detection with an accelerometer actigraph: comparisons with polysomnography. Physiol Behav 2001, 72:21-28.

22. Zeitzer JM, Dijk D-J, Kronauer RE, Brown EN, Czeisler CA: Sensitivity of the human circadian pacemaker to nocturnal light: Melatonin phase resetting and suppression. J Physiol (London) 2000, 526:695-702.

23. Brainard GC, Hanifin JP, Greeson JM, Byrne B, Glickman G, Gerner E et al.: Action spectrum for melatonin regulation in humans: Evidence for a novel circadian photoreceptor. J Neurosci 200I, 21:6405-64I2. 
24. Kripke DF, Ancoli-Israel S, Klauber MR, Wingard DL, Mason WJ, Mullaney DJ: Prevalence of sleep disordered breathing in ages 4064 years: A population-based survey. Sleep 1997, 20:65-76.

25. Radloff LS: The CES-D scale: A self-report depression scale for research in the general population. Applied Psychol Measurement 1977, I:385-401.

26. First MB, Spitzer RL, Gibbon M, Williams JBW: Structured Clinical Interview for DSM-IV Axis I Disorders - Non-patient Edition (SCID-I/NP, Version 2.0) New York City: New York State Psychiatric Institute; 1996.

27. Tuunainen A, Kripke DF, Elliott JA, Assmus JD, Rex KM, Klauber MR Langer RD: Depression and endogenous melatonin in postmenopausal women. I Affect Dis 2002, 69: I49-I 58.

28. Ancoli-Israel S, Kripke DF, Klauber MR, Mason WJ, Fell R, Kaplan O: Sleep disordered breathing in community-dwelling elderly. Sleep 1991, I 4(6):486-495.

29. Baldwin CM, Griffith KA, Nieto FJ, O'Connor GT, Walsleben JA, Redline S: The association of sleep-disordered breathing and sleep symptoms with quality of life in the sleep heart health study. Sleep 200I, 24:96-105.

30. Boland LL, Shahar E, Iber C, Knopman DS, Kuo TF, Nieto FJ: Measures of cognitive function in persons with varying degrees of sleep-disordered breathing: the Sleep Heart Health Study. J Sleep Res 2002, I I:265-272.

31. Kessler RC, Berglund P, Demler O, Jin R, Koretz D, Merikangas KR et al:: The epidemiology of major depressive disorder. JAMA 2003, 289:3095-3105.

\section{Pre-publication history}

The pre-publication history for this paper can be accessed here:

http://www.biomedcentral.com/1471-244X/4/8/prepub

\section{Publish with Biomed Central and every scientist can read your work free of charge}

"BioMed Central will be the most significant development for disseminating the results of biomedical research in our lifetime. "

Sir Paul Nurse, Cancer Research UK

Your research papers will be:

- available free of charge to the entire biomedical community

- peer reviewed and published immediately upon acceptance

- cited in PubMed and archived on PubMed Central

- yours - you keep the copyright 